\title{
Detection of cytokine producing cells in the synovial membrane from patients with rheumatoid arthritis
}

\author{
Ann-Kristin Ulfgren, Staffan Lindblad, Lars Klareskog, Jan Andersson, Ulf Andersson
}

\begin{abstract}
Objectives-To develop and evaluate a new immunohistochemical method to study the localisation and phenotype of individual cytokine producing cells in synovial biopsy specimens in rheumatoid arthritis.

Methods-Cryopreserved sections of synovial tissue from nine patients with rheumatoid arthritis were incubated with carefully selected cytokine specific antibodies detecting 19 different cytokines, after fixation of the specimens with paraformaldehyde and using saponin to permeabilise the cell membranes.

Results-The immunohistochemical method yielded reproducible and distinct staining patterns, in which the cytokines accumulated mainly in the Golgi apparatus of producer cells, indicating that the method preferentially detected local synthesis rather than cytokine uptake. The cytokine production patterns varied considerably between biopsy specimens from different patients.

Conclusion-The present modified immunohistochemical method may provide a simple and rapid way to determine the local production of a wide array of cytokines in the synovium. The data obtained with this method also indicated that more $T$ cell derived cytokines than previously recognised were present in active synovitis, as located and sampled by arthroscopy.
\end{abstract}

(Ann Rheum Dis 1995; 54: 654-661)

The role of different cytokines in the development of synovitis in rheumatoid arthritis (RA) has been a matter of considerable debate during recent years. Early studies showed that $\mathrm{T}$ lymphocytes infiltrating the rheumatoid synovial tissue expressed various cell surface activation markers, for example HLA-DR, ${ }^{12}$ suggesting that $T$ lymphocytes have an active role in the inflammatory process in the synovial membrane. $^{3}$ Later, results were presented that indicated an abundance of macrophage derived cytokines such as interleukin (IL)-1, IL-6, IL-8, tumour necrosis factor $\alpha$ (TNF $\alpha$ ), and granulocyte macrophage colony stimulating factor (GM-CSF), ${ }^{4-11}$ but a relative paucity of $\mathrm{T}$ cell cytokines such as IL-2, IL-3,
IL-4, and interferon gamma IFN $\gamma^{12-14}$ in the rheumatoid joint. These data provoked some doubts concerning the importance of $T$ cell activation in the pathogenesis of RA, ${ }^{15}$ but also called for more extensive studies on cytokine production at various stages of the development of synovitis.

A considerable number of studies have subsequently addressed the question of local cytokine production in the rheumatoid joint. Most of these studies, however, are associated with two distinct problems. First, all studies so far performed have analysed only a few cytokines at a time, which has limited comparative studies of the production of the wide array of cytokines that are now known to interact in a synergistic or antagonistic way in an inflammatory lesion. Second, the synovial tissues analysed have in most cases been obtained at orthopaedic surgery - that is, at late stages of disease.

To address both these problems, we aimed to develop methodology to detect a large number of simultaneously produced cytokines in arthroscopically obtained biopsy specimens from RA patients. We have developed and recently described a procedure used in human tonsils ${ }^{16}$ and rectal biopsy specimens ${ }^{17}$ based on immunohistochemical intracellular staining of cytokines by means of a combined technique of fixation and permeabilisation, ${ }^{18}$ which permits the quantitation of cells producing at least 19 different cytokines. Our handling and staining of the detergent exposed sections preserves the morphology of the intracellularly accumulated cytokines in a unique way. ${ }^{16-20}$ The aldehyde based fixation provides a significant advantage over acetone fixation in terms of morphological maintenance of the intracellular cytokine producing organelles, and saponins (plant glycosides with high affinity for cholesterol) have been used to permeabilise cells by intercalating cell membranes in a reversible fashion to replace cholesterol. As saponin interacts predominantly with cholesterol alone, much of the morphology of the membrane structure of cells fixed with paraformaldehyde is found to remain intact when examined under the microscope. ${ }^{1819}$

The present pilot study of synovial biopsy specimens from patients with RA aimed to demonstrate the feasibility and reproducibility of the method and to reveal the patterns of cytokine production in the patients studied. 


\section{Patients and methods}

\section{PATIENT SELECTION}

Synovial biopsy specimens were obtained from nine patients (six women, three men; ages 27-67 years) who fulfilled the American College of Rheumatology criteria for the diagnosis of RA. ${ }^{21}$ Seven of these patients were subjected to arthroscopic biopsy of the knee joints (patients 1-7) by means of an arthroscopic technique described previously. ${ }^{22}$ Biopsy specimens were taken from the part of synovium that was macroscopically most inflamed; synovial specimens were obtained from the wrists of two patients (patients 8 and 9) undergoing surgery in active synovitis. All the patients were receiving NSAIDs and one patient (No 3) was taking a slow acting drug (auranofin). The history of exacerbation of local synovitis ranged from six weeks to five years.

All patients gave their informed consent and approval was granted by the Ethics Committees at the Uppsala University and the Karolinska Institute, Stockholm.

\section{HANDLING OF BIOPSY SPECIMENS}

Specimens obtained from arthroscopic surgery were immediately snap frozen in liquid nitrogen and embedded in OCT compound (Tissue-Tek, Mites Elkhart, IN). Those obtained at hand surgery were snap frozen in liquid isopentane. All tissue were kept at $-70^{\circ} \mathrm{C}$ until sectioned.

\section{IMMUNOHISTOCHEMISTRY}

Cryostat sections $8 \mu \mathrm{m}$ thick were mounted on gelatin coated glass slides (Novakemi, Stockholm, Sweden) and fixed for 30 minutes in paraformaldehyde (PFA) and phosphate buffered saline (PBS) (4\% PFA-PBS Sigma

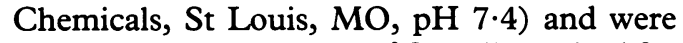
subsequently stored at $-20^{\circ} \mathrm{C}$ until required for staining. The initial step of the tissue staining was performed with $2 \%$ fetal calf serum in balanced salt solution (BSS) (Gibco Ltd, Paisley, UK) supplemented with $0 \cdot 1 \%$ saponin as a detergent (Riedel de Haen AG, Seelze, Germany) for seven to eight minutes at $37^{\circ} \mathrm{C}$ in order to reduce background signals caused by hydrophobic interactions. Endogenous peroxidase activity was blocked by $1 \%$ hydrogen peroxide and $2 \%$ sodium nitride dissolved in BSS-saponin for one hour at room temperature in the dark. After three additional washes in BSS-saponin, the slides were incubated overnight at room temperature in a humid chamber with $100 \mu$ l of a panel of carefully selected cytokine specific monoclonal antibodies (MAb) or affinity purified polyclonal antibodies at a concentration of 2-5 $\mu \mathrm{g} / \mathrm{ml}$ in BSS-saponin (table 1). Control stainings were performed in parallel with species and isotype matched myeloma proteins. The slides were then washed three times in BSS-saponin and incubated with $1 \%$ normal goat serum in BSS-saponin for 30 minutes at room temperature in order to reduce background signals caused by IgG Fc interactions by the biotinylated second step goat reagents. Biotin labelled secondary antibodies, absorbed against human Ig (biotin goat antimouse IgG1 and IgG2b, Caltag Lab, South San Francisco, CA; biotin goat antirat IgG, Vector Lab, Burlingame, CA) were used diluted 1:300 during a 30 minute incubation at room temperature. After subsequent washes in BSS-saponin, the slides were incubated either with avidin-biotin-horseradish peroxidase (Vectastain, ABC-HP-kit, Vector Lab), or with avidin-biotin-alkaline phosphatase (Vectastain, ABC-AP-kit, Vector Lab). Colour reaction was developed by diaminobenzidine (DAB) $0.5 \mathrm{mg} / \mathrm{ml}$ or an alkaline phosphatase substrate kit including levamisol-blocking endogenous alkaline phosphatase (Vector Lab). The reaction field was blocked after five to 30 minutes by three washes in BSS, counterstained with Mayer's haematoxylin, dehydrated in ethanol, and mounted in a glycerin buffer.

A sequential staining technique was used for two colour immunohistochemical analysis. The single colour stain was initially performed as described above for visualisation of cytokine producing cells using the alkaline phosphatase and monoclonal antialkaline phosphatase technique. ${ }^{30}$ The complex of alkaline phosphatase and $\mathrm{MAb}$ antialkaline-phosphatase was detected by alkaline phosphatase substrate (red). The sections were then incubated with

Table 1 Cytokine specific antibodies used for tissue staining

\begin{tabular}{|c|c|c|c|c|}
\hline Cytokine & Antibody & Isotype & Producer & Reference \\
\hline IL-1 $\alpha$ & $1277-89-7,1277-82-29,1279-143-4$ & mouse IgG1 & H Towbin, Ciba-Geigy, Basel & 23 \\
\hline IL-1 $\beta$ & $2-\mathrm{D}-8$ & mouse IgG1 & H Towbin, Ciba-Geigy, Basel & 23 \\
\hline IL-1 ra & $1384-92-17-19$ & mouse IgG1 & H Towbin, Ciba-Geigy, Basel & 23 \\
\hline IL-2 & MQ1-17H12 & rat IgG2a & J Abrams, DNAX, Palo Alto, CA & 24 \\
\hline IL-3 & BVD3-IF9, BVD8-6G8 & rat IgG1 . & J Abrams, DNAX, Palo Alto, CA & 24 \\
\hline IL-4 & MP4-25D2 & rat IgG1 & J Abrams, DNAX, Palo Alto, CA & 24 \\
\hline IL-5 & JES-39D10 & rat IgG2a & J Abrams, DNAX, Palo Alto, CA & 24 \\
\hline IL-6 & $M Q 2-6 A 3$ & rat IgG & J Abrams, DNAX, Palo Alto, CA & 24 \\
\hline IL-8 & NAP-1 & mouse IgG1 & M Ceska, Sandoz, Vienna & 25 \\
\hline IL-10 & JES3-19FI, JES3-12G8 & rat IgG2a & J Abrams, DNAX, Palo Alto, CA & 24 \\
\hline $\mathrm{IL}-13$ & JES8-5A2, JES8-30F11 & rat IgG2a & J Abrams, DNAX, Palo Alto, CA & 26 \\
\hline GM-CSF & BVD2-21C11, BVD2-5A2 & rat IgG2a & J Abrams, DNAX, Palo Alto, CA & 24 \\
\hline G-CSF & BVD13-3A5, BVD11-37G10 & rat IgG & J Abrams, DNAX, Palo Alto, CA & 24 \\
\hline TNF $\alpha$ & MP9-20A4 & rat IgG & J Abrams, DNAX, Palo Alto, CA & 24 \\
\hline TNF $\beta$ & LTX22 & mouse IgG1 & G Adolf, Bender Medsystems, Vienna & 27 \\
\hline IFN $\gamma$ & DIK1 & mouse IgG1 & G Andersson, Astra-Drako, Lund & 28 \\
\hline TGF $\beta 1$ & K96 & polyclonal rabbit IgG & K Miyazono, Ludwig Institute, Uppsala & 29 \\
\hline TGF $\beta 2$ & K94 & polyclonal rabbit IgG & K Miyazono, Ludwig Institute, Uppsala & 29 \\
\hline TGF $\beta 3$ & K95 & polyclonal rabbit IgG & K Miyazono, Ludwig Institute, Uppsala & 29 \\
\hline LTBP & AB39 & polyclonal rabbit IgG & K Miyazono, Ludwig Institute, Uppsala & 29 \\
\hline
\end{tabular}


a second biotinylated BSS-saponin diluted $\mathrm{MAb}$ for phenotyping of cells, which was developed by avidin-biotin-horseradish peroxidase and DAB for peroxidase staining (brown).

\section{SPECIFICITY TESTS}

Highly purified natural or recombinant cytokines were used to block specific cytokine staining. The appropriate cytokine was added (in excess, at a concentration of $20-50 \mu \mathrm{g} / \mathrm{ml}$ ) to its corresponding cytokine specific antibody $(2-5 \mu \mathrm{g} / \mathrm{ml})$ at $4^{\circ} \mathrm{C}$ overnight. Staining with the complex was performed as described previously and compared with results obtained by combining anticytokine $\mathrm{MAb}$ preincubated with other cytokines as a control.

The following cytokines were used in these specificity tests: natural IL-1 $\alpha$ (Dr C Heusser, Basel) and IL-1 $\beta$ (Dr C Dinarello, Boston), recombinant (r) IL-1ra (Dr H Towbin, Basel), rIL-2, rIL-3, rIL-4, rIL-5, rIL-6, rIL-8 (Genzyme Corp, Boston), rIL-8 (Dr Ceska, Vienna), natural IL-10 (Dr J Abrams, Palo Alto), rTNF $\alpha$ and rTNF $\beta$ (Bayer Inc, Hannover), rIFN $\gamma$ (Boehringer Ingelheim Inc, Vienna), rGM-CSF (Sandoz Inc, Basel), recombinant granulocyte colony stimulating factor (rG-CSF) (Hoffman La-Roche, Basel) and bovine transforming growth factor (TGF) $\beta 1$ (Dr C Snapper, Bethesda), rTGFß2 (Genzyme, Boston), and large latent TGF $\beta$ complexes (Dr K Miyazono, Ludwig Institute, Uppsala).

\section{QUANTIFICATION OF STAINED CELLS}

For identification, cytokine producing areas were visualised in a Reichert-Jung microscope (Polyvar II, Reichert-Jung, Vienna) under $\times 100$ magnification. Cytokine expression was assessed as the number of positively stained cells of the whole tissue section. Positively stained cells were scrutinised in high power fields ( $\times 400$ magnification). The area of each section was measured by a computerised image analyser (Quantimet 570, Leica-Cambridge Ltd, Cambridge, UK). All microscopic evaluations were performed by one observer (AU) on three different occasions to exclude within observer variation; very similar results were obtained. All samples were also assessed by another observer (LK) and the results agreed very well with those of the first observer. The incidence of cytokine producing cells per total area of cryocut sections was quantified according to a scoring system: $0=$ negative cell staining; $1=0-5$ positively stained cells; $2=5-10$ positively stained cells; $3=$ more than 10 positively stained cells. The scores represent means of numbers obtained at three different assessments.

\section{Results}

MORPHOLOGY OF CYTOKINE STAINING IN SYNOVITIS

The intracellular cytokine staining pattern for most interleukins revealed by immunohisto- chemical staining of synovial membrane sections was cytoplasmic (figs 1,2 ), and cytokine producing cells tended to be present in clusters in the tissue. The morphology of this intracellular staining in certain cells was localised in a characteristic juxtanuclear position reflecting the accumulation of synthesised cytokines in the Golgi organelle of producer cells. ${ }^{19}$ In contrast, but in agreement with our previous results obtained with in vitro activated cells in suspension, ${ }^{23}$ immunohistochemical staining in tissue sections for IL- $1 \alpha$, IL-1 $\beta$, and IL-1 ra showed a diffuse nuclear and cytosolic distribution, without any localised intracellular accumulation (fig $1 \mathrm{~F}$, G).

In addition to cytoplasmically stained cells, we observed an immunoreactivity extending over extracellular areas surrounding producer cells, mainly in stainings for GM-CSF (fig $2 \mathrm{~F}$ ), G-CSF, IL-1 ra (fig 1G), IL-3, IL-8, IFN $\gamma$ (fig 2D), TGF $\beta 2$ (fig 1C), TGF $\beta 3$ and the latent TGF $\beta$ binding protein (LTBP) (fig 1D), the transport protein for TGF $\beta$. The specificities of the extracellular and the intracellular immunoreactivity were verified by their complete inhibition by preincubation of the cytokine specific $\mathrm{MAb}$ with the relevant corresponding human cytokines, but not with other cytokines (fig 1B $v 1 \mathrm{C}$ ).

A total of nine different synovial tissues were stained with antibodies against 19 different cytokines (table 1). Production of one or several of these cytokines was detected in all of the synovial biopsy specimens, although with a very heterogenous pattern of production among the patients studied (table 2). Positive control stainings were performed using antiCD3 and anti-HLA-DR antibodies which showed the expected increased HLA-DR expression and extensive $T$ cell infiltration in all specimens examined (fig 2A)-an appearance characteristic for diagnosis of RA. ${ }^{31}$ Mouse, rat or rabbit myeloma proteins were used as negative control staining antibodies; these control stainings were negative in all but two biopsy specimens (from patients 2 and 6 ), both of which contained rheumatoid factor producing cells in the synovial membranes. As the positively stained cells in these biopsy specimens appeared morphologically to be plasma cells, we assume that the background signals were caused by intracellularly produced $\mathrm{RF}$ interacting with exogenous Ig used for staining. ${ }^{32}$

IDENTIFICATION OF MONOKINE PRODUCTION There was great variation between patients in production of cytokines known to be produced mostly by macrophages (IL- $1 \alpha$, IL- $1 \beta$, IL- 1 ra, IL-6, IL-8, TNF $\alpha$, GM-CSF and G-CSF) (table 2). The three different types of IL-1 were found to be coexpressed in different combinations in individual biopsy specimens, or were not expressed at all. IL-1 $\beta$ producing cells outnumbered those of IL-1 $\alpha$ : IL- $1 \alpha$ was found in four of nine tissues, but IL-1 $\beta$ in seven of nine patients; IL-1 ra was evident in six of eight synovial tissues examined. Staining for 


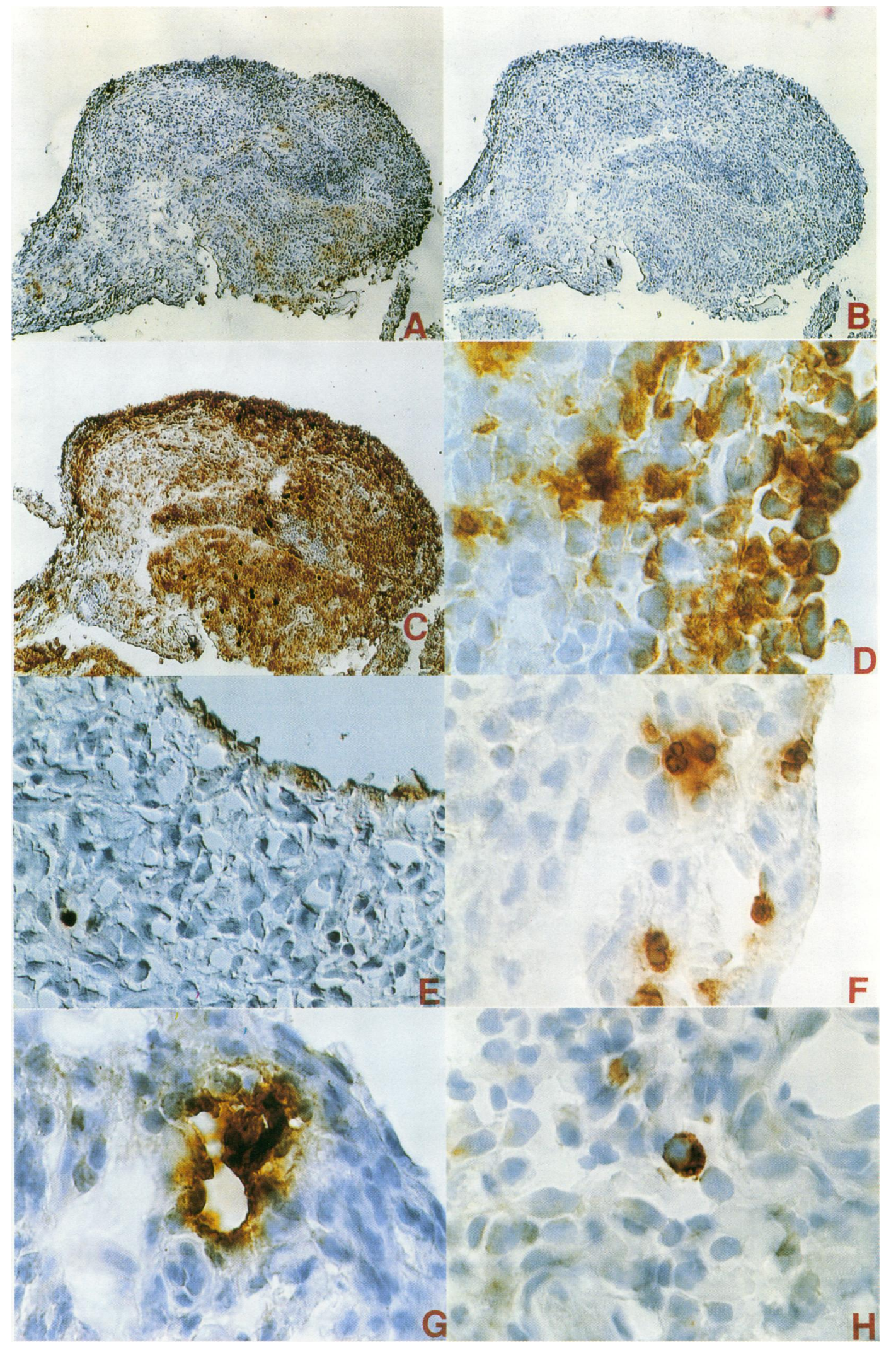

Figure 1 Videoprint photographs illustrating brown immunoperoxidase staining for cytokine producing cells in cryopreserved synovial membrane biopsy specimens arthroscopically obtained from $R A$ patients $(A-D=$ patient 6 in table $2, E, F=$ patient 3 ; $G, H=$ patient 5). Counterstain: haematoxylin. A: Staining for TGFB1: combined intra- and extracellular deposition of the cytokine. (Original magnification $\times 80$.) $\quad$ B: Elimination of TGF $\beta 2$ staining shown in C by preincubation of the anti-TGF $\beta 2$ antibodies with recombinant TGF $\beta 2$ as a specificity control. (Original magnification $\times 80$.) C: TGF 32 staining of $a$ consecutive section without any addition of exogenous TGF $\beta 2$. The production of this isoform was more pronounced than that of TGF $\beta 1$. Individual producer cells and prominent extracellular presence of the cytokine are demonstrated. (Original

magnification $\times 80$.) D: Staining in a consecutive section for latent TGF $\beta$ binding protein (LTBP), the transport protein for $T G F \beta$. (Original magnification $\times 800$.) $E:$ TNF $\alpha$ production in the lining layer and in scattered cells in the deeper layers. (Original magnification $\times 500$.) $\quad F: I L-1 \beta$ producing cells. Note the distinct staining of both the cytoplasm and the nucleus of producer cells - a pattern characteristic of IL-1 staining. (Original magnification $\times 1000$.) G: IL-1 ra production expressed in the endothelium of a blood vessel. Strong nuclear staining, analogous to the appearance with IL-1 $\beta$. (Original magnification $\times 800$.) H: Typical appearance of local juxtanuclear deposition of IL-5 in a producer cell indicates the accumulation of the cytokine in the Golgi organelle. No extracellular deposition. (Original magnification $\times 800$.) 


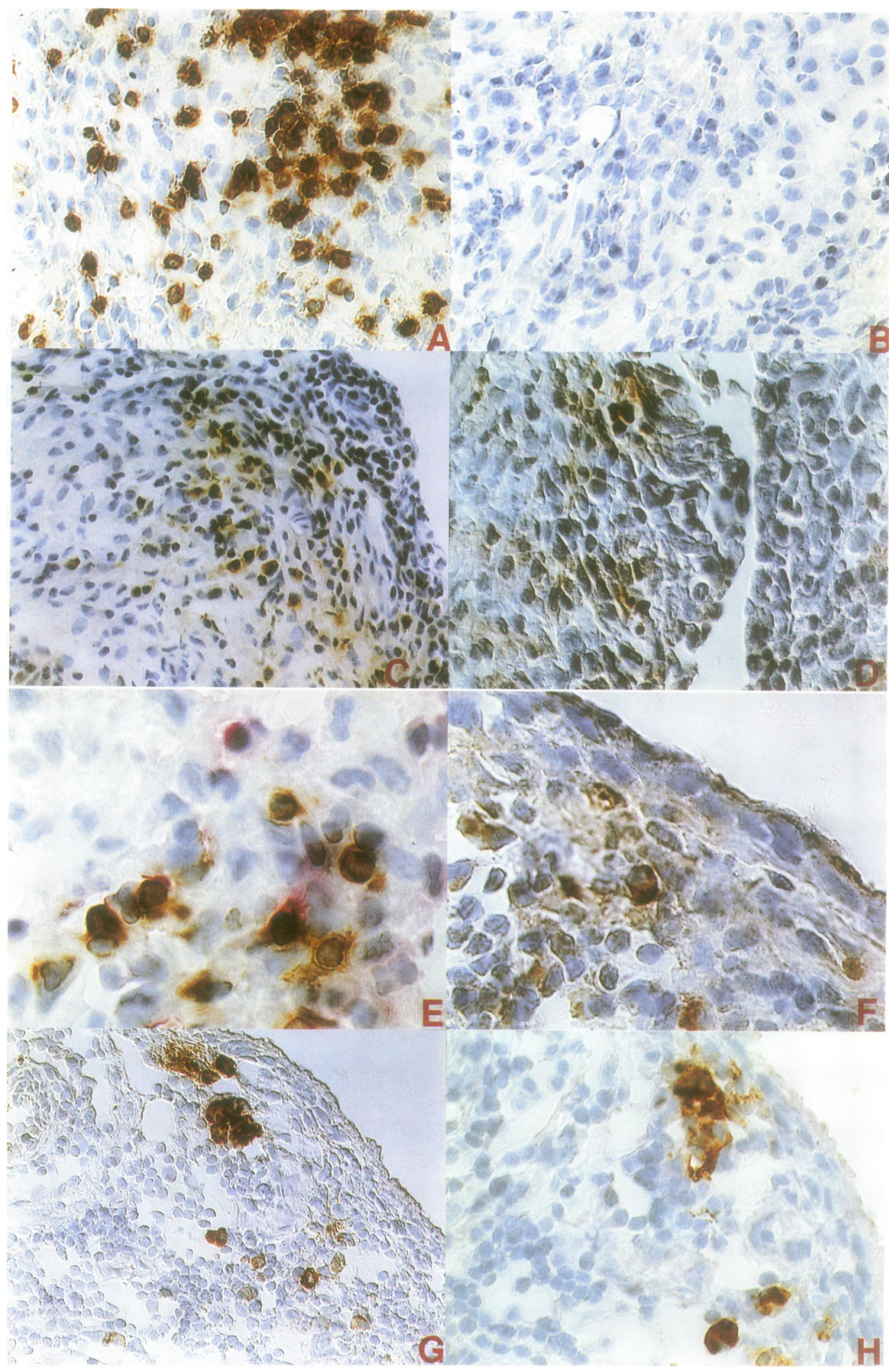

Figure 2 Immunohistochemical staining, mainly of lymphokines, in synovial biopsy specimens from patient $2(A-F)$ and patient $4(G-H) . \quad A:$ Cluster of infiltrating CD3 positive lymphocytes in the synovial membrane. CD3 staining (brown) performed in the presence of the detergent saponin demonstrates both cytoplasmic and membrane immunoreactivity.

(Original magnification $\times 400$.) B: Control staining with irrelevant isotype matched myeloma protein and indirect immunoperoxidase technique without any background signals. (Original magnification $\times 320$.) C: IL-2 staining of an active $T$ cell infiltrate demonstrating multiple producer cells. Note the additional entrapping of IL-2 in the extracellular area close to the synthesising cells. (Original magnification $\times 200$.) D: IFN $\gamma$ producing cells in another lymphoid infiltrate. (Original magnification $\times 320$ ) E: Two colour staining of IL-4 producing cells (red alkaline phosphatase) and CD 3 (brown peroxidase). IL-4 production is demonstrated in both CD3 positive and CD 3 negative cells. (Original magnification $\times 1000$.) F: GM-CSF production. The cytokine is expressed in the Golgi stack of producer cells and extracellularly around synthesising cells. (Original magnification $\times 1000$.) G: IL-10 producing cells predominantly localised in clusters. (Original magnification $\times 320$.) H: $I L-13$ producing cells. (Original magnification $\times 500$.) 
Table 2 Enumeration of cytokine producing cells per section in synovial biopsies from $R A$ patients

\begin{tabular}{|c|c|c|c|c|c|c|c|c|c|}
\hline Patient & $\begin{array}{l}\text { Section area } \\
\left(\mathrm{mm}^{2}\right)\end{array}$ & $I L-2$ & $I L-3$ & $I L-4$ & $I L-5$ & $I L-10$ & $I L-13$ & $I F N \gamma$ & $T N F \beta$ \\
\hline $\begin{array}{l}1 \\
2 \\
3 \\
4 \\
5 \\
6 \\
7 \\
8 \\
9\end{array}$ & $\begin{array}{r}5 \cdot 2 \\
7 \cdot 4 \\
9 \cdot 0 \\
20 \cdot 7 \\
7 \cdot 8 \\
7.5 \\
2 \cdot 0 \\
3 \cdot 1 \\
10.5\end{array}$ & $\begin{array}{l}0 \\
2 \\
1 \\
1 \\
1 \\
2 \\
0 \\
0 \\
0\end{array}$ & $\begin{array}{l}1 \\
3 \\
1 \\
3 \\
0 \\
3 \\
0 \\
3 \\
1\end{array}$ & $\begin{array}{l}0 \\
3 \\
2 \\
0 \\
3 \\
3 \\
0 \\
3 \\
1\end{array}$ & $\begin{array}{l}1 \\
0 \\
0 \\
0 \\
2 \\
3 \\
0 \\
1 \\
1\end{array}$ & $\begin{array}{l}0 \\
3 \\
1 \\
3 \\
2 \\
2 \\
0 \\
0 \\
1\end{array}$ & $\begin{array}{l}0 \\
3 \\
0 \\
3 \\
1 \\
3 \\
0 \\
0 \\
1\end{array}$ & $\begin{array}{l}0 \\
3 \\
1 \\
1 \\
3 \\
2 \\
0 \\
3 \\
0\end{array}$ & $\begin{array}{l}0 \\
3 \\
1 \\
3 \\
1 \\
1 \\
0 \\
0 \\
0\end{array}$ \\
\hline Patient & $\begin{array}{l}\text { Section area } \\
\left(\mathrm{mm}^{2}\right)\end{array}$ & $G-C S F$ & $G M-C S F$ & $T N F \alpha$ & $I L-1 \alpha$ & $I L-1 \beta$ & $I L-1 r a$ & $I L-6$ & $I L-8$ \\
\hline $\begin{array}{l}1 \\
2 \\
3 \\
4 \\
5 \\
6 \\
7 \\
8 \\
9\end{array}$ & $\begin{array}{r}5 \cdot 2 \\
7 \cdot 4 \\
9.0 \\
20 \cdot 7 \\
7 \cdot 8 \\
7.5 \\
2 \cdot 0 \\
3 \cdot 1 \\
10.5\end{array}$ & $\begin{array}{l}0 \\
3 \\
3 \\
0 \\
3 \\
2 \\
0 \\
2 \\
2\end{array}$ & $\begin{array}{l}3 \\
3 \\
2 \\
1 \\
3 \\
3 \\
0 \\
1 \\
1\end{array}$ & $\begin{array}{l}0 \\
1 \\
2 \\
2 \\
2 \\
0 \\
0 \\
1 \\
3\end{array}$ & $\begin{array}{l}0 \\
0 \\
0 \\
1 \\
1 \\
1 \\
0 \\
0 \\
1\end{array}$ & $\begin{array}{l}1 \\
3 \\
3 \\
0 \\
1 \\
1 \\
0 \\
3 \\
3\end{array}$ & $\begin{array}{l}2 \\
0 \\
1 \\
3 \\
2 \\
2 \\
\text { nd } \\
1 \\
0\end{array}$ & $\begin{array}{l}2 \\
1 \\
0 \\
0 \\
2 \\
1 \\
0 \\
2 \\
1\end{array}$ & $\begin{array}{l}0 \\
1 \\
3 \\
1 \\
2 \\
1 \\
0 \\
1 \\
3\end{array}$ \\
\hline Patient & $\begin{array}{l}\text { Section area } \\
\left(\mathrm{mm}^{2}\right)\end{array}$ & $T G F \beta 1$ & $T G F \beta 2$ & $T G F \beta 3$ & $L T B P$ & $\begin{array}{l}\text { Mouse } \\
\text { IgG1 }\end{array}$ & $\begin{array}{l}\text { Rat } \\
\text { IgG1 }\end{array}$ & $\begin{array}{l}\text { Rat } \\
\text { IgG2a }\end{array}$ & \\
\hline $\begin{array}{l}1 \\
2 \\
3 \\
4 \\
5 \\
6 \\
7 \\
8 \\
9\end{array}$ & $\begin{array}{r}5 \cdot 2 \\
7 \cdot 4 \\
9 \cdot 0 \\
20 \cdot 7 \\
7 \cdot 8 \\
7 \cdot 5 \\
2 \cdot 0 \\
3 \cdot 1 \\
10 \cdot 5\end{array}$ & $\begin{array}{l}\text { nd } \\
\text { nd } \\
3 \\
2 \\
\text { nd } \\
1 \\
0 \\
3 \\
2\end{array}$ & $\begin{array}{l}\text { nd } \\
\text { nd } \\
1 \\
2 \\
0 \\
3 \\
3 \\
3 \\
3\end{array}$ & $\begin{array}{l}1 \\
\text { nd } \\
3 \\
3 \\
\text { nd } \\
3 \\
0 \\
3 \\
3\end{array}$ & $\begin{array}{l}\text { nd } \\
\text { nd } \\
\text { nd } \\
2 \\
\text { nd } \\
3 \\
3 \\
3 \\
3\end{array}$ & $\begin{array}{l}0 \\
t \\
0 \\
0 \\
0 \\
\dagger \\
0 \\
0 \\
0\end{array}$ & $\begin{array}{l}0 \\
\dagger \\
1 \\
0 \\
0 \\
t \\
0 \\
0 \\
0\end{array}$ & $\begin{array}{l}\text { nd } \\
\dagger \\
0 \\
0 \\
\text { nd } \\
t \\
0 \\
0 \\
0\end{array}$ & \\
\hline
\end{tabular}

Scoring system for incidence of cytokine producing cells per cryocut section: $0=$ negative cel staining; $1=0-5$ positively stained cells; $2=5-10$ positively stained cells; $3=>10$ positively stained cells.

†Synovial membrane contained rheumatoid factor producing plasma cells.

these three proteins was located primarily in irregularly shaped macrophage like cells, which were situated in both the lining layer and the sublining layer (fig $1 \mathrm{~F}$ ). IL-1 ra production was also demonstrated in endothelial cells of blood vessels (fig $1 G$ ). Staining for $T N F \alpha$ was evident in six of nine tissues and was present mainly within the lining layer (fig $1 \mathrm{E}$ ).

GM-CSF antibody gave a strong positive reaction in eight of nine tissues, in most cases more widespread than that for either TNF $\alpha$ or IL-1. Staining for GM-CSF was particularly prominent in the lining layer and, notably, there was also a pronounced extracellular staining for GM-CSF in five of nine tissues (fig 2F). G-CSF antibodies yielded positive staining in six of nine tissues and this was also combined with a substantial extracellular staining, particularly in the sublining layer. IL-8 staining was present in seven of nine tissues, where it was most conspicuous in the lining layer and in fibrotic areas. Many IL-8 positive cells resembled fibroblasts morphologically.

IDENTIFICATION OF TGF $\beta$

The intensity of TGF $\beta$ staining was impressive and the frequency of TGF $\beta 2$ producing cells, in particular (fig 1C), outnumbered that of all other studied cytokines. The consistent extracellular localisation of large amounts of TGF $\beta$ suggested a localised storage depot in the tissues. Most regions staining for TGF $\beta$ coexpressed LTBP, the transport protein for TGF $\beta$, indicating that the extracellular presence of TGF $\beta$ was a consequence of active secretion, rather than a result of leakage of latent TGF $\beta$ complexes (fig 1D).

IDENTIFICATION OF LYMPHOKINE PRODUCTION Staining for IFN $\gamma$ was seen in six of nine tissues (fig 2D) and that for IL-2 in five of nine tissues (fig 2C). Typically, the vast majority of CD3 positive $T$ cells did not show any signs of IFN $\gamma$ or IL-2 synthesis, but positive staining for each of these cytokines was preferentially located within certain aggregates of $\mathrm{CD} 3$ positive cells, other apparently identical $\mathrm{T}$ cell clusters being completely negative for IL-2 and IFN $\gamma$.

TNF $\beta$ was found in five of nine biopsy specimens, mainly at the sites that stained for $T N F \alpha$, although the TNF $\beta$ staining was more limited. One biopsy specimen showed TNF $\beta$ producing cells, but no evidence of $\mathrm{TNF} \alpha$ production.

With the present methodology, very distinctly positive IL-4 staining was evident both in small lymphocyte like cells and within larger irregular cells in six of nine tissues. Two colour staining for surface CD3 antigens and intracellular IL-4 demonstrated that IL-4 production occurred in $T$ cells and in non- $T$ cells (fig 2E). A further, notable feature of IL-4 staining was that the positively stained cells were often present in lymphoid clusters, which sometimes also contained IL-2 and IFN $\gamma$ producing cells. The synthesis of these various cytokines occurred in distinctly separate cells. The recently described T cytokine, IL-13 (a $T$ cell lymphokine with many functional properties shared by IL-4 and IL-10), was identified in five of nine patients; its tissue localisation was approximately the same as that of IL-4 (fig $2 \mathrm{H}$ ). In addition, IL-10 producing cells were demonstrated in six of nine tissues (fig 2G). Producer cells were either small round mononuclear cells in perivascular lymphoid aggregates, or larger irregular cells located mainly in or close to the lining layer.

Staining patterns for IL-3 and IL-5 (fig $1 \mathrm{H}$ ), which can be synthesised by $T$ cells and by mast cells, resembled each other: positively stained cells were in both cases either small round mononuclear cells or large irregular cells. Most cells expressing these two cytokines were found in the lining or sublining layer.

\section{Discussion}

Three findings of potential interest are described in the present report. The main finding is the demonstration of positive intracytoplasmic staining for a large number of simultaneously synthesised human cytokines in synovial biopsy specimens from RA patients. The second finding concerns the large diversity of patterns of cytokine production seen in biopsy specimens displaying similar histopathological features and staining profiles for conventional lymphocyte and macrophage cell surface markers. The third observation is that of a substantial presence of $\mathrm{T}$ cell derived cytokines (IL-2, IL-4, IL-5, IL-10, IL-13, 
IFN $\gamma$ and TNF $\beta$ ) at a protein level in synovial biopsy specimens obtained from active inflammation in rheumatoid arthritis identified visually via the arthroscope.

Our technique for both fixation and permeabilisation, combined with staining with 19 different cytokine antibodies selected very carefully from a total pool of several thousand different MAbs, should confer certain advantages compared with previously described methods for detection of local cytokine production in synovitis. The technique gives a considerably clearer staining morphology to intracellular organelles than do other methodologies, thereby apparently also permitting a distinction to be made, on frozen sections, between local production of a cytokine and the presence of a cytokine which had been produced elsewhere. ${ }^{16-18}$ The intracellular staining of cytokines confined to the Golgi apparatus (with the exception of IL-1 cytokines) has previously mainly been used in in vitro model systems, ${ }^{19}$ in which it has been shown to correlate well with the production of cytokine mRNA ${ }^{20}$ and cytokine secretion in supernatants. ${ }^{19} 20$ This colocalization was confirmed by two colour staining with Golgi specific and cytokine specific MAb. ${ }^{16}{ }^{19}$ No such comprehensive methodology has previously been described for the detection of distinct sites of local cytokine production in sections taken from tissues in active synovitis, and some cytokines studied here, such as IL-5 and IL-13, have not previously been demonstrated in the rheumatoid synovial membrane.

None of the selected cytokine specific MAbs used in the present study has been successfully used in parallel control experiments with standard immunohistochemical techniques based on acetone fixation. However, using other cytokine detecting MAbs in acetone fixed synovial membrane sections, we have demonstrated positive immunoreactions. The disadvantage has been that it has proved impossible to discriminate between cytokine producing cells and cytokine binding cells, as the dominating signals in the acetone fixed material were generated from cell surface membranes. Acetone fixation seems to permit detection of antigen on cell surfaces in a much more satisfactory way than PFA-saponin treatment, which instead preserves the morphology of intracellular antigens in a superior state. In order to identify cytokine producing cells, there is a clear need to distinguish target cells from producer cells.

One of the more interesting potentials of the present metholology is concerned with the need for a technique for repeated and rapid analysis of cytokine production in sequentially acquired synovial biopsy specimens from patients during the course of their disease and during the institution of various treatment regimens affecting cytokine regulation. The present study demonstrates that distinct staining patterns can be identified in biopsy specimens acquired by arthroscopy. However, it will be important to perform additional studies of the local variability of cytokine production within a given joint before embarking on larger clinical follow up programmes.

The diversity of the patterns of staining for cytokine production in the synovia studied, and the presence of $\mathrm{T}$ cell cytokines in certain biopsy specimens deserve special attention. The results from staining studies in some of the synovial tissues clearly correspond well with previously reported data on the predominance of mainly monocyte/macrophage derived cytokines (such as IL-1, IL-6, IL-8, TNF $\alpha$, GM-CSF, and G-CSF) in the rheumatoid joint. ${ }^{4-11}$ The strong staining for the three isoforms of TGF $\beta$ in certain tissues also agrees with findings of earlier reports. ${ }^{33}$ Studies of T cell cytokines at a protein level in the rheumatoid joint have been more scarce, and it was therefore of particular interest to observe distinct production of many putatively $T$ cell derived cytokines such as IL-2, IL-3, IL-4, IL-5, IL-10, IL-13, IFN $\gamma$, and TNF $\beta$ in clusters of cells having lymphocyte morphology, in several biopsy specimens obtained from active synovitis in rheumatoid arthritis. We believe that we have managed to obtain these new results because of our meticulous selection of cytokine detecting antibodies and our tissue handling technique. The $\mathrm{T}$ cell origin of some of the IL- 4 production was confirmed by two colour staining for surface CD3 markers and intracellular IL-4 (fig 2E). Some of these lymphoid aggregates demonstrated simultaneous production of lymphokines mediating cytotoxicity and macrophage activation (Th1 response), such as IL-2 and IFN $\gamma$, and lymphokines promoting antibody formation (Th2 response), such as IL-4, IL-10, and IL13. These clusters were often seen adjacent to lymphoid infiltrates having identical histopathological features without any signs of current cytokine production.

As to the meaning of these staining patterns, it is immediately apparent that we do not as yet have enough information from basic model systems on similar comprehensive patterns of cytokine production to provide an adequate interpretation. Thus we do not know how the pattern of cytokine production develops during various phases of a classically $T$ cell mediated inflammatory reaction, for example a delayed hypersensitivity reaction. Nor do we know enough about these events at various stages in animal models of chronic $\mathrm{T}$ cell dependent inflammatory arthritides such as collagen arthritis or adjuvant arthritis. The limited experience available has been obtained with in vivo model systems of experimental encephalitis in rats. ${ }^{34}$ These studies have demonstrated substantial differences in cytokine patterns at various stages of disease, with more $\mathrm{T}$ cell derived cytokines in the initial phase, and more macrophage derived cytokines (and in particular increased amounts of TGF $\beta$ ) in late and remitting stages of the disease. ${ }^{34}$ Present knowledge based on extrapolations from these experimental encephalitis studies suggests that patterns of cytokine production observed in some biopsy specimens from patients with active RA are compatible 
with that of a $\mathrm{T}$ cell dependent chronic inflammatory disease. Clearly, however, studies to date on cytokine patterns in human and experimental disease represent only the beginning of a more comprehensive descriptive analysis which is required to further understanding of the role of local cytokine regulation in chronic inflammation and subsequently to direct our efforts to modify this regulation.

Also of relevance to the subject of the present study is the need for such descriptive studies to be undertaken with due consideration of the clinical and local status of the disease processwhich by implication necessitates the acquisition of biopsy specimens via arthroscopy, preferentially repeatedly in longitudinal studies. We believe that the technique we describe for rapid analysis of a large number of cytokines will be helpful in the exploration of pathogenetic mechanisms in $R A$ and the evaluation of new therapeutic regimens.

This study was supported by grants from the Swedish Medical Research Council (grants Nos 09082 and 10850), Axel Johnsson's Foundation, the National Cancer Institute (grants Nos 2490 and 2766), the Swedish Association against Rheumatism, von Kantzow's Foundation, Crafoord's Foundation, Nanna Svartz's Foundation, af Ugglas' Foundation, King Gustaf V:s Foundation and Thuring's Foundation. We gratefully acknowledge the gift of cytokine specific antibodies from John Abrams (Palo Alto), Gunther Adolf (Vienna), Gudrun Andersson (Lund), Miroslav Ceska (Vienna), Kohei Miyazono (Uppsala) and Harry Towbin (Basel).

1 Burmester G R, Yu D T Y, Irani A-M, Kunkel H G, Winchester $\mathrm{R} \mathrm{J}$. Ia+ $\mathrm{T}$ cells in synovial fluid and tissue of patients with rheumatoid arthritis. Arthritis Rheum 1981; 24: 1370-6.

2 Klareskog L, Forsum U, Malmnäs-Tjernlund D, Kabelitz D, Wigren A. Appearance of anti-HLA DR reactive cells in normal and rheumatoid synovial tissue. Scand F Immunol 1981; 14: 183-92.

3 Panayi G S, Lanchbury J S, Kingsley G H. The importance of the $T$ cell in initiating and maintaining the chronic synovitis of rheumatoid arthritis. Arthritis Rheum 1992 35: 729-35.

4 Fontana A, Hengartner H, Weber E, Fehr K, Grob P J, Cohen G. Interleukin-1 activity in the synovial fluid of patients with rheumatoid arthritis. Rheumatol Int 1982; 2: 49-53.

5 Buchan G, Barrett K, Turner M, Chantry D, Maini R N, Feldmann $M$. Interleukin-1 and tumor necrosis factor mRNA expression in rheumatoid arthritis: prolonged production of IL-1 $\alpha$. Clin Exp Immunol 1988; 73: 449-53.

6 Hirano $T$, Matsuda $T$, Turner $M$, et al. Excessive production of interleukin $6 / \mathrm{B}$ cell stimulatory factor- 2 in production of interleukin 6/B cell stimulatory factor-2 in
rheumatoid arthritis. Eur $f$ Immunol 1988; 18: 1797-801.

7 Brennan F M, Zachariae C O C, Chantry D, et al. Detection of interleukin-8 biologic activity in synovial fluids from patients with rheumatoid arthritis and production of interleukin-8 mRNA by isolated synovial cells. Eur $\mathcal{f}$ Rheumatol 1990; 20: 2141-4.

8 Chu C Q, Field M, Feldman M, Maini R N. Localisation of tumor necrosis factor $\alpha$ in synovial tissue and at the cartilage-pannus junction in patients with rheumatoid arthritis. Arthritis Rheum 1991; 34: 1125-32.

$9 \mathrm{Xu}$ W D, Firestein G S, Taetle R, Kaushansky K, Zvaifler N J. Cytokines in chronic inflammatory arthritis II. Granulocyte-macrophage colony-stimulating factor in rheumatoid synovial effusions. $\mathcal{f}$ Clin Invest 1989; 83: 876-82.

10 Firestein G S, Berger A E, Tracey D E, et al. IL-1 receptor antagonist protein production and gene expression in rheumatoid arthritis and osteoarthritis synovium f Immunol 1992; 149: 1054-62.

11 Yanni G, Farahat M N M R, Poston R N, Panayi G S Intramuscular gold decreases cytokine expression and macrophage numbers in the rheumatoid synovial membrane. Ann Rheum Dis 1994; 53: 315-22.
12 Husby G, Williams R. Immunohistochemical studies of interleukin-2 and interferon- $\gamma$ in rheumatoid arthritis. Arthritis Rheum 1985; 28: 174-81.

13 Firestein G S, Xu W-D, Townsend $K$, et al. Cytokines in chronic inflammatory arthritis $I$. Failure to detect $T$ cell lymphokines (interleukin 2 and interleukin 3) and presence of macrophage colony-stimulating (CSF-1) and a novel mast cell growth factor in rheumatoid synovitis. f Exp Med 1988; 168: 1573-86.

14 Miossec P, Naviliat M, D'Angeac A, Sany J, Banchereau J. Low levels of interleukin-4 and high levels of transforming growth factor- $\beta$ in rheumatoid synovitis. Arthritis Rheum growth factor- $\beta$ in

15 Firestein G S, Zvaifler N J. How important are T cells in chronic rheumatoid synovitis? Arthritis Rheum 1990; 33: 768-73.

16 Andersson J, Björk L, Ågren K, Abrams J, Litton M, Andersson $U$. Concomitant in vivo production of 19 different cytokines in human tonsils. Immunology 1994 83: 16-24.

17 Raqib R, Lindberg A A, Wretlind B, Bardhan P K Andersson U, Andersson J. Persistence of local cytokine production in Shigellosis in acute and convalescent stages. Infect Immun 1995; 63: 289-96.

18 Andersson U, Andersson J. Immunolabelling of cytokineproducing cells in tissues and in suspension. In: Fradelizie D, Emelie D, eds. Cytokine producing cells. Paris: INSERM, 1994; 48-64.

19 Sander B, Andersson J, Andersson U. Assessment of cytokines by immunofluorescence and the paraformaldehyde/saponin procedure. Immunol Rev 1991; 119: 65-93.

20 Dolhain R J E M, Andersson U, ter Haar N T, et al. Detection of intracellular IFN $\gamma$ by light microscopy using an immunoperoxidase technique: Correlation with the corresponding mRNA and protein product. $f$ Leukocyte Biol 1993; 54: 545-51.

21 Arnett F C, Edworthy S M, Bloch D A, et al. The American Rheumatism Association 1987 revised criteria for the classification of rheumatoid arthritis. Arthritis Rheum 1987; 31: 315-24.

22 Lindblad S, Klareskog L, Hedfors E, Forsum U, Sundström C. Phenotypic characterization of synovial tissue in situ in different types of synovitis. Arthritis Rheum 1983; 26: 1321-32.

23 Andersson J, Björk L, Dinarello C A, Towbin H, Andersson U. Lipopolysaccharide induces human interleukin-1 receptor antagonist and interleukin-1 production in the same cell. Eur $\mathcal{F}$ Immunol 1992; 22: 617-23.

24 Abrams J S, Roncarolo M-G, Yssel H, Andersson U, Gleich G I, Silver J E. Strategies of anti-cytokine monoclonal antibody development: Immunoassay of IL-10 and IL-5 in clinical samples. Immunol Rev 1993; 127: 5-24.

25 Agace W, Hedges S, Andersson J, Andersson U, Svanborg C. Selective cytokine production in epithelial cells after activation with E. coli. Infect Immun 1993; 61: 602-9.

26 Mctivation with E. coli. Infect Immun 1993; 61: 602-9. Interleukin-13, a novel $T$ cell-derived cytokine that Interleukin-13, a novel $T$ cell-derived cytokine that regulates human monocyte and B
Acad Sci USA 1993; 90: 3735-42.

27 Andersson U, Adolf G, Dohlsten M, Möller G, Sjögren H-O. Characterization of individual tumor necrosis factor $\alpha$ - and $\beta$-producing cells after polyclonal $T$ cell activation. $\mathcal{f}$ Immunol Methods 1989; 123: 233-8.

28 Andersson G, Ekre H-P, Alm G, Perlmann P. Monoclona antibody two-site ELISA for human IFN- $\gamma$. Adaptation for determinants in human serum or plasma. 7 Immunol Methods 1989; 125: 89-95.

29 Olofsson A, Miyazono K, Kanzaki T, Colosetti P, Engström U, Heldin C-H. Transforming growth factor $\beta-1,-2$ and -3 secreted by a human glioblastoma cell line. $\not$ Biol Chem 1992; 267: 19482-8.

30 Cordell J L Falini B, Erber W N, Ghosh A K Abdulaziz Z, Macdonald S. Immunoenzymatic labeling of monoclonal antibodies using immune complexes of alkaline phosphatase and monoclonal anti-alkaline phosphatase (APAAP complexes). $\mathcal{F}$ Histochem Cytochem 1984; 32: $219-29$.

31 Lindblad S, Hedfors E. Intraarticular variation in synovitis. Local macroscopic and microscopic signs of inflammatory activity are significantly correlated. Arthritis Rheum 1985; 28: $977-86$.

32 Klareskog L, Rubin K, Holmdahl R. Binding of collagen type II to rheumatoid synovial cells. Scand $\mathcal{f}$ Immunol type If to rheumat

33 Taketazu $\mathrm{F}$, Kato $M$, Gobl A, et al. Enhanced expression of TBF- $\beta$ s and TGF- $\beta$ type II receptor in the synovial of TBF- $\beta$ s and TGF- $\beta$ type II receptor in the synovial tissues of patients

34 Issazadeh S, Mustaf M, Ljungdahl $\AA$, et al. IFN- $\gamma$, IL-4 and TGF- $\beta$ in experimental autoimmune encephalomyelitis in Lewis rats; dynamics of cellular mRNA expression in the central nervous system and lymphoid cells. $\mathscr{f}$ Neuroscience 1995 . In press. 